\title{
Comparison of the acute-phase response after laparoscopic versus open aortobifemoral bypass surgery: a substudy of a randomized controlled trial
}

\author{
This article was published in the following Dove Press journal: \\ Vascular Health and Risk Management \\ 26 September 2016 \\ Number of times this article has been viewed
}

\author{
Anne H Krog ${ }^{1,2}$ \\ Mehdi Sahba ${ }^{3}$ \\ Erik M Pettersen ${ }^{4}$ \\ Irene Sandven ${ }^{5}$ \\ Per M Thorsby 1,6 \\ Jørgen J Jørgensen ${ }^{1,2}$ \\ Jon O Sundhagen ${ }^{2}$ \\ Syed SS Kazmi \\ 'Institute of Clinical Medicine, \\ University of Oslo, ${ }^{2}$ Department \\ of Vascular Surgery, Division of \\ Cardiovascular and Pulmonary \\ Diseases, Oslo University Hospital, \\ Oslo, ${ }^{3}$ Department of Vascular \\ Surgery, Østfold Central Hospital, \\ Fredrikstad, ${ }^{4}$ Department of Vascular \\ Surgery, Sørlandet Hospital HF, \\ Kristiansand, ${ }^{5}$ Oslo Center for \\ Biostatistics and Epidemiology \\ (OCBE), ${ }^{6}$ Hormone Laboratory, \\ Department of Medical Biochemistry, \\ Oslo University Hospital, Oslo, \\ Norway
}

Correspondence: Anne H Krog Institute of Clinical Medicine, University of Oslo, PO Box II7I, Blindern, 03 I8 Oslo, Norway

Tel +479l792938

Email a.h.krog@medisin.uio.no
Purpose: Minimally invasive surgical techniques have been shown to reduce the inflammatory response related to a surgical procedure. The main objective of our study was to measure the inflammatory response in patients undergoing a totally laparoscopic versus open aortobifemoral bypass surgery. This is the first randomized trial on subjects in this population.

Patients and methods: This is a substudy of a larger randomized controlled multicenter trial (Norwegian Laparoscopic Aortic Surgery Trial). Thirty consecutive patients with severe aortoiliac occlusive disease eligible for aortobifemoral bypass surgery were randomized to either a totally laparoscopic $(n=14)$ or an open surgical procedure $(n=16)$. The inflammatory response was measured by perioperative monitoring of serum interleukin-6 (IL-6), IL-8, and C-reactive protein (CRP) at six different time points.

Results: The inflammatory reaction caused by the laparoscopic procedure was reduced compared with open surgery. IL-6 was significantly lower after the laparoscopic procedure, measured by comparing area under the curve (AUC), and after adjusting for the confounding effect of coronary heart disease $(P=0.010)$. The differences in serum levels of IL- 8 and CRP did not reach statistical significance.

Conclusion: In this substudy of a randomized controlled trial comparing laparoscopic and open aortobifemoral bypass surgeries, we found a decreased perioperative inflammatory response after the laparoscopic procedure measured by comparing AUC for serum IL-6.

Keywords: inflammation, vascular, laparoscopy, surgery, interleukin, C-reactive protein

\section{Introduction}

Every surgical trauma initiates a certain extent of inflammatory response, which is a part of our immune system. ${ }^{1}$ However, if excessive, this response can be autodestructive and may lead to complications after surgery. ${ }^{2}$ The quantification of this inflammatory process can be used as a measurement for surgical trauma, ${ }^{3,4}$ as well as a prognostic tool. ${ }^{5-7}$ Several studies have shown reduced physiological immune response when comparing minimally invasive surgical techniques to the traditional methods. ${ }^{8-11}$ Laparoscopic surgery causes less tissue trauma than open surgery and seems to preserve better immune function. ${ }^{12,13}$ Interleukin-6 (IL-6) is higher after major abdominal surgery and lower after laparoscopic surgery as compared to open surgery. ${ }^{2,14,15}$ Studies show that patients undergoing laparoscopic aortobifemoral bypass (LABF) surgery have a low postoperative morbidity and mortality. ${ }^{16-18}$ In addition, a recently 
published comparative cohort study showed significantly lower composite end point of all-cause mortality, systemic morbidity, and graft thrombosis after LABF compared with open aortobifemoral bypass (OABF). ${ }^{19}$

In this randomized study, we aimed to compare the totally LABF with OABF for the treatment of aortoiliac occlusive disease (AIOD) on the basis of postoperative changes in inflammatory mediators. Only one previous trial has measured the acute-phase response in patients undergoing an LABF, but the trial was not randomized and the hand-assisted minilaparotomy approach was used. ${ }^{20}$

\section{Hypothesis}

LABF surgery induces a reduced systemic inflammatory response compared with $\mathrm{OABF}$.

\section{Patients and methods Design}

This study is a part of an ongoing multicenter, randomized controlled trial (Norwegian Laparoscopic Aortic Surgery Trial [NLAST]) at the Department of Vascular Surgery, Oslo University Hospital. Patients with severe symptomatic AIOD, classified according to the Trans-Atlantic Inter-Society Consensus (TASC) II as type D lesions, were randomized to either $\mathrm{LABF}$ or OABF procedure. ${ }^{21}$

\section{Participants}

Participants were included from three vascular surgery departments in the South-East region of Norway, based on the following inclusion and exclusion criteria.

Inclusion criteria:

- Patient with AIOD, TASC type D lesion, ${ }^{21}$ and symptoms in the form of

- intermittent claudication, with walking distance $<200 \mathrm{~m}$ and/or

- chronic critical lower limb ischemia with rest pain or ischemic ulcers (duration of symptoms $>2$ weeks).

Exclusion criteria:

- Eligible for an endovascular procedure

- COPD stage IV or more severe, GOLD classification ${ }^{22}$

- Symptomatic coronary heart disease

- Chronic heart failure, ejection fraction $<40 \%$

- Active cancer disease

- Hostile abdomen, previous major abdominal surgery

- Abdominal aortic aneurysm $\geq 3.0 \mathrm{~cm}$

- Acute critical limb ischemia (duration of symptoms $\leq 2$ weeks).

\section{Sample size}

This was a substudy in a larger randomized trial, and an individual power analysis was not conducted on these outcomes.

\section{Randomization and blinding}

The patients were enrolled by clinicians and researchers and were randomized to either open or laparoscopic surgery. We used block randomization, with six patients in each block and different sequences for the three participating hospitals. The sequence was random and was not known by the researchers. It was contained in closed, opaque, sequentially numbered envelopes until randomization. Blinding of surgeon and/or participants after randomization was not possible, but laboratory technicians who analyzed the samples were blinded.

\section{Intervention}

All procedures were performed by a team with at least one consultant vascular surgeon. The laparoscopic surgeons were passed the learning curve. ${ }^{19,23}$ The patients underwent aortobifemoral bypass surgery with either a totally laparoscopic approach in accordance with the technique described by Coggia et $\mathrm{al}^{24}$ or a standard open procedure through a median laparotomy. Aortic clamp was placed just below the renal arteries or just above if suprarenal aortic clamping was necessary. Both procedures were performed under general anesthesia.

\section{Ethics}

The project was completely voluntary and participants gave informed, written consent. The trial was approved by the Regional Committee for Medical and Health Research Ethics, South-East Norway (registration number 2012/1367), and establishment of a biological bank was approved by the Norwegian Data Inspectorate.

\section{Registration}

The trial (NLAST) and protocol were registered at www.clinicaltrials.gov with the registration number NCT01793662.

\section{Outcomes}

Our primary outcome was inflammation due to surgical trauma measured by detecting serum changes in IL-6, IL-8, and $\mathrm{C}$-reactive protein (CRP).

\section{Biochemical analysis}

We chose to measure IL-6, IL-8, and CRP due to their validity in reflecting the level of acute-phase response in major aortic surgery. ${ }^{20,25}$ The time points were chosen to capture fluctuation over time. IL-6 and IL-8 usually peak during the first 24 hours 
postoperatively, but CRP peaks at a later time..$^{10,25,26}$ Blood samples were taken at the following six different time points:

1. Before surgery

2. After completion of distal anastomosis and flow to one of the lower limbs was reestablished

3. Six hours after beginning of surgery

4. Twelve hours after beginning of surgery

5. Twenty-four hours after beginning of surgery

6. At discharge from hospital.

Blood samples were primarily taken from arterial catheter, or if not possible, from central venous catheter or peripheral vein. Samples were centrifuged at $4^{\circ} \mathrm{C}, 1106 \mathrm{~g}$ within 1 hour from sampling. Two milliliters of serum sample was frozen in plastic Nunc vials, within 2 hours from sampling, at $-80^{\circ} \mathrm{C}$ until further analysis.

\section{Procedure for analysis}

IL-6 and IL-8 were analyzed at the Hormone Laboratory, Oslo University Hospital, using the MILLIPLEX Map human High Sensitivity T-cell Magnetic Bead Panel (HSTCMAG28SK, MILLIPLEX ${ }^{\circledR}$ Map Kit; EMD Millipore Corporation, Billerica, MA, USA), while the serum CRP level was analyzed using the immune turbidimetric method performed by an automated machine from ROCHE Module PE Core P800 \& E170 Chemistry Analyzer (Hoffmann-La Roche Ltd., Basel, Switzerland).

\section{Statistics}

Categorical variables were summarized as frequencies and continuous variables by the median and interquartile range. Comparisons between the two treatment groups were performed using the Mann-Whitney $U$-test for continuous variables and Fisher's exact test for categorical variables. A graphical presentation of the mean serum levels of the inflammatory markers was plotted in SPSS, including calculation of mean and confidence interval for each time point. The three inflammatory markers (CRP, IL-6, and IL-8) were considered as continuous outcomes and measured at four fixed time points for all the subjects. These serial measurements were analyzed univariately, calculating the area under the curve (AUC). ${ }^{27}$ Differences in AUC between the two groups were evaluated by a parametric test. All markers were analyzed in their logged form due to skewed distribution of data. A multivariate analysis was performed, based on the general estimated equations (GEE) model. In this method, the correlation structure of the data is specified by the investigators at the outset, and the model iterates toward a stable set of estimates to the parameters, ${ }^{28}$ controlling for confounders or risk factors. Time points two and six were not taken at a fixed point in time (reestablishment of flow through graft and discharge from hospital) and were consequently removed from the AUC and GEE analyses to minimize variability and make the models more robust. Statistical significance was set at a 5\% level $(P<0.05)$. We used software from Epi Info (Epi Info $^{\mathrm{TM}}$ software; Center for Disease Control and Prevention, Atlanta, GA, USA), IBM SPSS statistics version 22.0 (IBM Corporation, Armonk, NY, USA), MedCalc version 13.1.2 (MedCalc Software, Ostend, Belgium), and Stata 13.0 (StataCorp LP, College Station, TX, USA).

\section{Results}

\section{Participant flow and recruitment}

Thirty consecutive patients from the participating hospitals were included from February, 2013 to January, 2015 and randomized to either LABF $(n=14)$ or OABF $(n=16)$ (Figure 1). The patient baseline characteristics in the two groups are given in Table 1. One patient was converted from laparoscopic to open surgery and was analyzed in the laparoscopic group, as intention to treat. No patients were excluded after randomization or lost to follow-up at the time of analysis. There were no missing values in the inflammation markers. This substudy trial was completed after the inclusion of 30 patients.

\section{Outcomes and estimation}

In Figures 2-4, a graphical presentation of the serum levels of IL-6, IL-8, and CRP is given. All the inflammatory

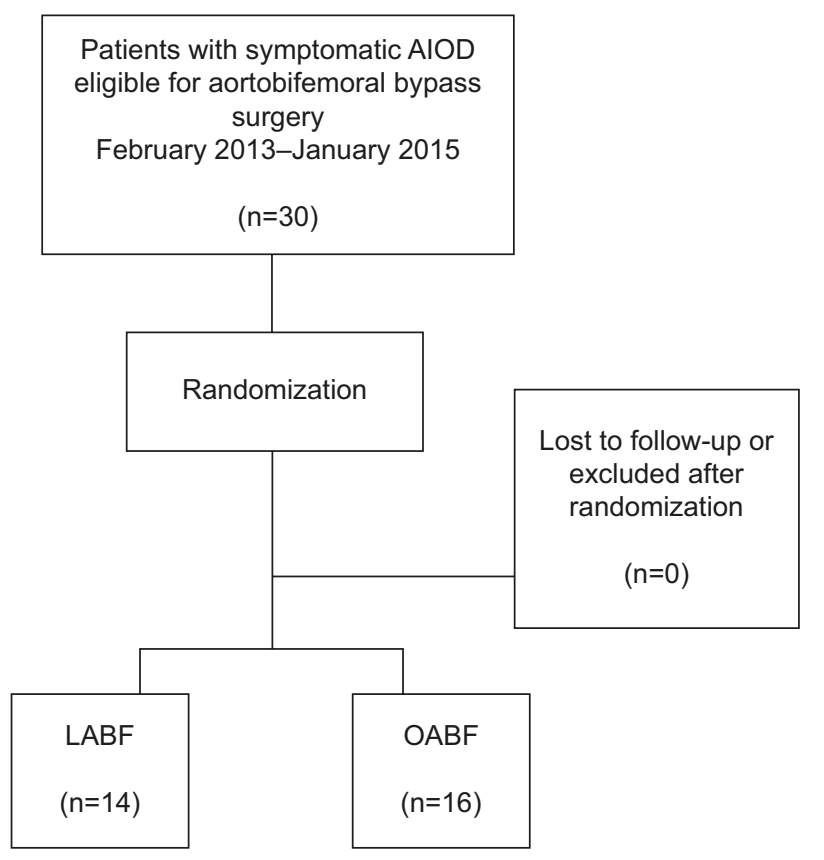

Figure I Flowchart of patient population with aortoiliac occlusive disease (AIOD) treated with totally laparoscopic aortobifemoral bypass (LABF) or open aortobifemoral bypass (OABF). 
Table I Baseline characteristics of patients treated with either totally laparoscopic or open aortobifemoral bypass for severe aortoiliac occlusive disease

\begin{tabular}{|c|c|c|c|}
\hline Baseline characteristics & $\begin{array}{l}\text { Laparoscopy } \\
(\mathrm{N}=14)\end{array}$ & $\begin{array}{l}\text { Open surgery } \\
(\mathrm{N}=16)\end{array}$ & $P$-value \\
\hline Age (years), mean (SD) & $59(7.2)$ & $64(6.8)$ & $0.1043^{d}$ \\
\hline Female sex, $\mathrm{N}(\%)$ & $7(50)$ & $9(56)$ & $0.5095^{\mathrm{e}}$ \\
\hline Body mass index $\left(\mathrm{kg} / \mathrm{m}^{2}\right)$, mean $(\mathrm{SD})$ & $26.3(4.2)$ & $24.0(5.1)$ & $0.2056^{d}$ \\
\hline Current smoker, $\mathrm{N}(\%)$ & $7(50)$ & $10(63)$ & $0.1038^{e}$ \\
\hline Hypertension, N (\%) & $10(7 I)$ & II (69) & $1.0000^{\mathrm{e}}$ \\
\hline Renal failure, $\mathrm{N}(\%)$ & $0(0)$ & $I(6)$ & $1.0000^{\mathrm{e}}$ \\
\hline COPD, N (\%) & $4(29)$ & $3(19)$ & $0.6746^{\mathrm{e}}$ \\
\hline Hyperlipidemia, N (\%) & $5(36)$ & $2(13)$ & $0.2040^{\mathrm{e}}$ \\
\hline Diabetes mellitus, N (\%) & I (7.I) & $0(0)$ & $0.4667^{\mathrm{e}}$ \\
\hline Coronary heart disease, $\mathrm{N}(\%)$ & $2(14)$ & $5(3 I)$ & $0.3992^{\mathrm{e}}$ \\
\hline Statin, N (\%) & $12(86)$ & $15(94)$ & $0.5862^{\mathrm{e}}$ \\
\hline Acetylsalicylic acid, N (\%) & $13(93)$ & $15(94)$ & $1.0000^{\mathrm{e}}$ \\
\hline \multicolumn{4}{|l|}{ ASA classification ${ }^{\mathrm{a}}$} \\
\hline ASA class $2, \mathrm{~N}(\%)$ & $0(0)$ & I (6) & $1.0000^{\mathrm{e}}$ \\
\hline ASA class $3, \mathrm{~N}(\%)$ & $14(100)$ & $15(94)$ & \\
\hline \multicolumn{4}{|l|}{ Fontaine classification ${ }^{\mathrm{b}}$} \\
\hline Fontaine class $3, \mathrm{~N}(\%)$ & II (79) & $12(75)$ & $1.0000^{\mathrm{e}}$ \\
\hline Fontaine class $4, \mathrm{~N}(\%)$ & $3(2 I)$ & $4(25)$ & \\
\hline Critical limb ischemia, $\mathrm{N}(\%)$ & $3(2 I)$ & $4(25)$ & $1.0000^{\mathrm{e}}$ \\
\hline Ankle brachial index (preoperative), median (IQR) & $0.57(0.40-0.60)$ & $0.37(0.27-0.50)$ & $0.0083^{d}$ \\
\hline
\end{tabular}

Notes: ${ }^{2}$ American Society of Anesthesiologists (ASA) classification; ${ }^{\mathrm{b}}$ Fontaine classification (classification of symptoms in peripheral atherosclerotic disease); $\mathrm{AB}$ ( preoperative) in leg with lowest $\mathrm{ABI}$; 'Mann--Whitney U-test; and 'Fisher's exact test.

Abbreviations: $A B I$, ankle brachial index; IQR, interquartile range; $S D$, standard deviation.

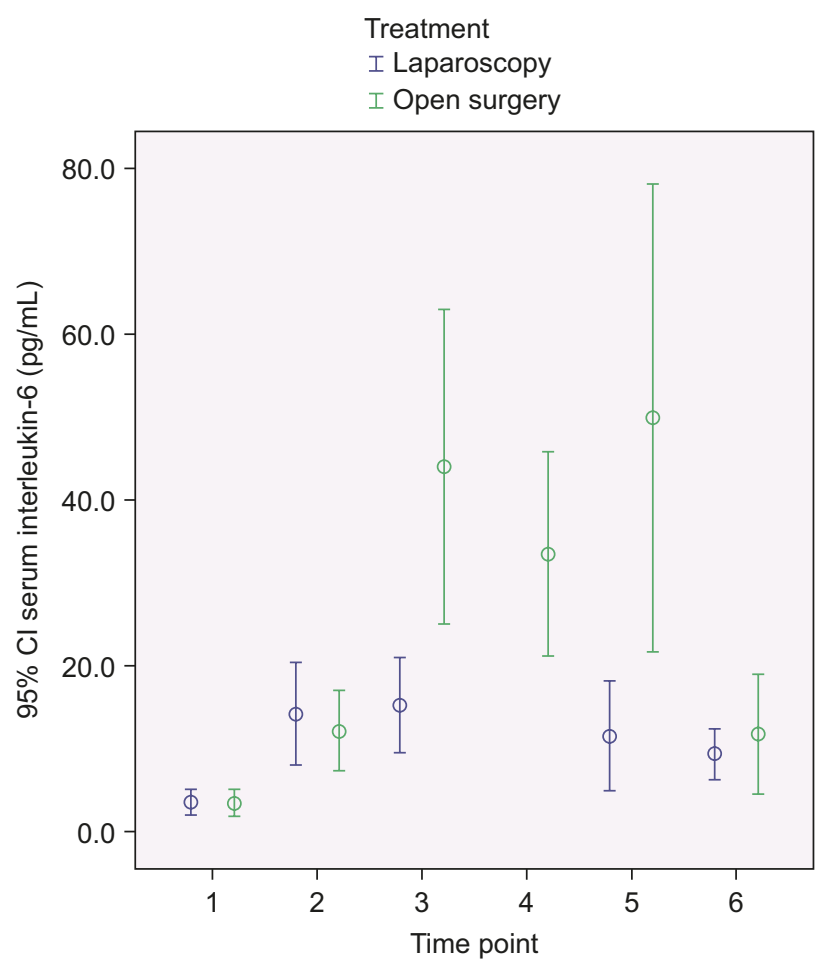

Figure 2 Comparing mean serum level of interleukin-6 $(\mathrm{pg} / \mathrm{mL})$ at different time points during and after totally laparoscopic aortobifemoral bypass (LABF) versus open aortobifemoral bypass (OABF).

Notes: Error bars represent the $95 \%$ confidence interval $(\mathrm{Cl})$. Timepoints: I, before surgery; 2, after completion of distal anastomosis and flow to one of the lower limbs was reestablished; 3, 6 hours after beginning of surgery; 4, 12 hours after beginning of surgery; 5,24 hours after beginning of surgery; 6 , at discharge from hospital.

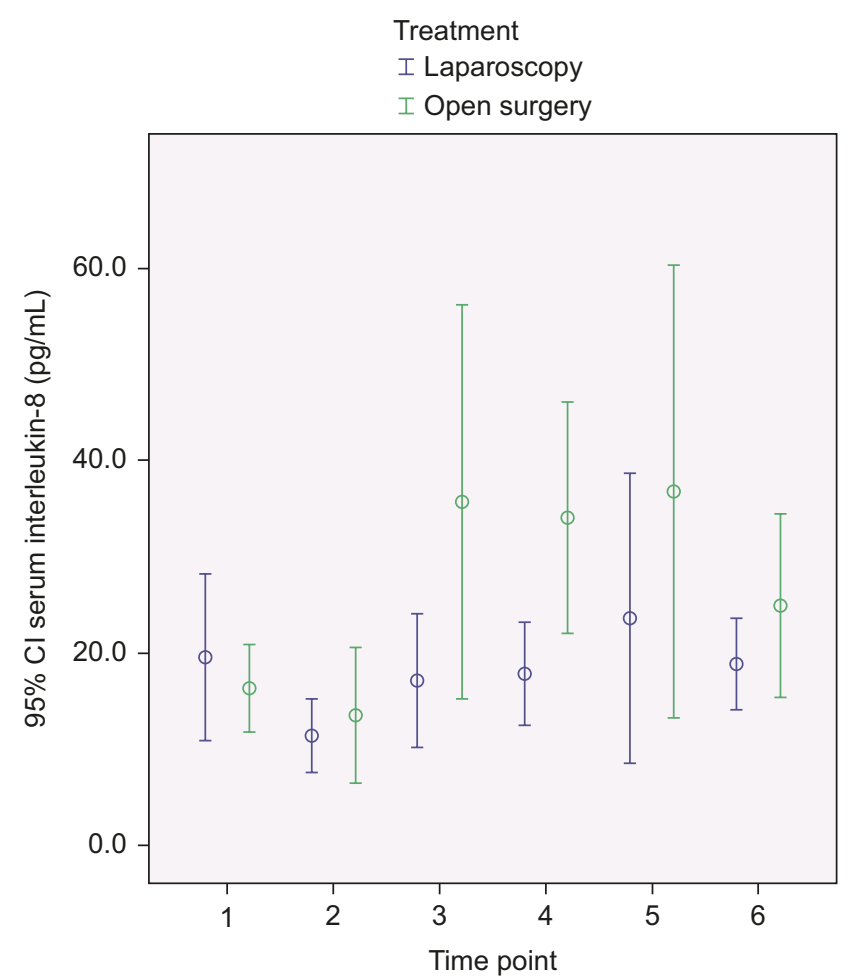

Figure 3 Comparing mean serum level of Interleukin-8 $(\mathrm{pg} / \mathrm{mL})$ at different time points during and after totally laparoscopic aortobifemoral bypass (LABF) versus open aortobifemoral bypass (OABF).

Notes: Error bars represent the $95 \%$ confidence interval $(\mathrm{Cl})$. Timepoints: I, before surgery; 2 , after completion of distal anastomosis and flow to one of the lower limbs was reestablished; 3, 6 hours after beginning of surgery; 4,12 hours after beginning of surgery; 5,24 hours after beginning of surgery; 6 , at discharge from hospital. 


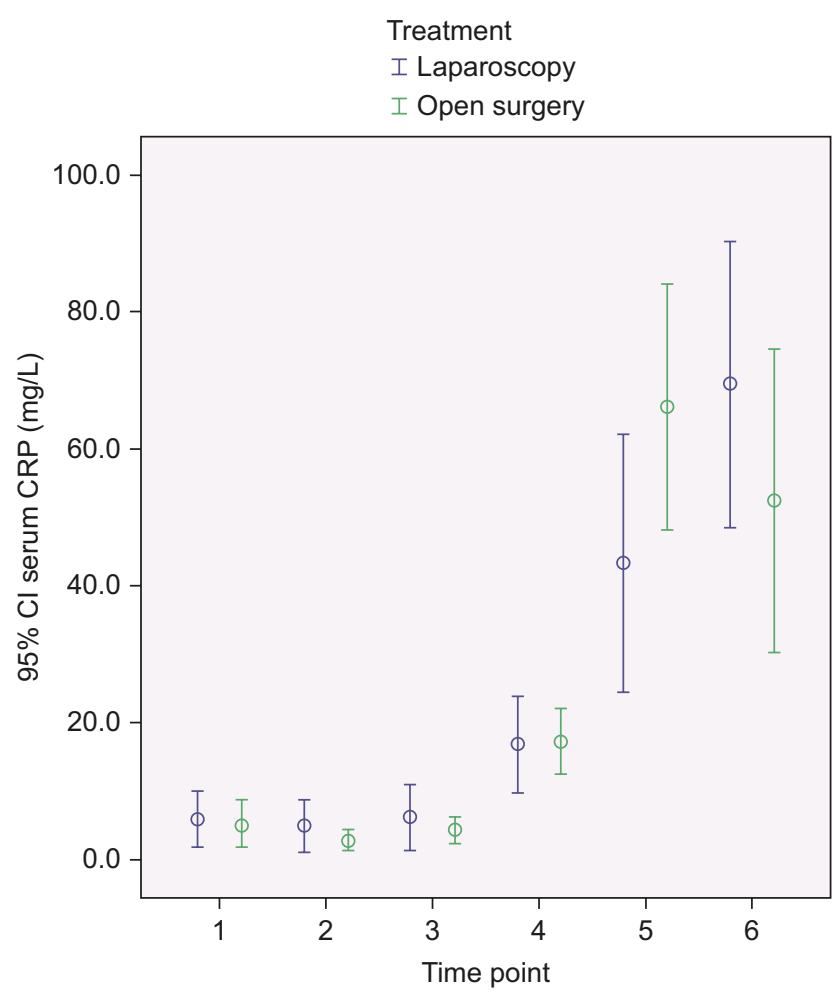

Figure 4 Comparing mean serum level of C-reactive protein (CRP) (mg/L) at different time points during and after totally laparoscopic aortobifemoral bypass (LABF) versus open aortobifemoral bypass (OABF).

Notes: Error bars represent the $95 \%$ confidence interval $(\mathrm{Cl})$. Timepoints: I, before surgery; 2, after completion of distal anastomosis and flow to one of the lower limbs was reestablished; 3, 6 hours after beginning of surgery; 4, 12 hours after beginning of surgery; 5,24 hours after beginning of surgery; 6 , at discharge from hospital.

markers increased after surgery compared with baseline. When comparing the individual time point measurements, serum levels of IL-6 was significantly lower after LABF when compared with $\mathrm{OABF}$ at 6,12 , and 24 hours postoperatively (Figure 2). The differences in serum levels of IL-8 and CRP did not reach statistical significance (Figures 3 and 4).

When comparing the summary of the repeated measurements by AUC, mean level of IL-6 was still lower in patients undergoing LABF as compared to OABF (Table 2). No statistically significant difference in the mean level of IL-8 or $\mathrm{CRP}$ was found in patients undergoing LABF compared with
OABF when comparing AUC (Table 2). After controlling for the confounding effect of coronary heart disease in a final multivariate analysis (Table 3), IL-6 was still significantly lower in the LABF group $(P=0.010)$, and the confounding effect was small ( $8.8 \%)$. There was no statistically significant difference in IL-8 or CRP.

Operation-related parameters are given in Table 4. Patients treated with a laparoscopic procedure had a longer aortic clamping time when compared with those treated with open surgery, but significantly less bleeding during surgery. There were only two patients with suprarenal aortic clamping, lasting for only 5 minutes (LABF) versus 3 minutes (OABF).

Clinical outcomes are described in Table 5. The patients had significantly shorter hospital stay in the laparoscopic group. There was no statistical difference in postoperative morbidity, and none of the patients died during the study period.

\section{Discussion}

There was significantly decreased serum levels of IL- 6 after LABF compared with OABF, measured by comparing AUC and after controlling for interdependence and the confounding effect of coronary heart disease (CHD; $P=0.010)$. The differences in serum levels of IL-8 and CRP did not reach statistical significance.

The inflammatory response is an interaction of a number of mediators. ${ }^{29}$ IL-6 is a key agent in the inflammatory process $^{30}$ and is higher after major abdominal surgery and lower after laparoscopic surgery when compared with open surgery. ${ }^{2,14,15}$ The manipulation and damage of the peritoneum in laparotomy may be one of the causes. ${ }^{31}$ IL-8 activity correlates with IL-6 levels after injury or surgical trauma and influences the level of circulating granulocytes and attracts them to the site of injury. ${ }^{29,32}$ Both IL- 6 and IL- 8 correlate with the duration of surgery, blood loss, and extent of tissue trauma, among other things. ${ }^{33}$ IL-6 induces CRP production. ${ }^{34}$ CRP in turn binds to phosphocholine on damaged cells and microorganisms, which activates the complement pathway

Table 2 Comparison of area under curve (AUC) in laparoscopic aortobifemoral bypass (LABF) versus open aortobifemoral bypass (OABF) for the serum levels of interleukin-6 (IL-6), IL-8, and C-reactive protein (CRP)

\begin{tabular}{|c|c|c|c|c|c|c|c|c|c|}
\hline $\begin{array}{l}\text { Inflammation } \\
\text { marker }\end{array}$ & Treatment & $\mathbf{N}$ & Median & Mean & $\begin{array}{l}\text { Logged } \\
\text { mean }\end{array}$ & SD & $\begin{array}{l}\text { Difference in } \\
\text { logged mean }\end{array}$ & $t_{d f=28}$ & $P$-value \\
\hline \multirow[t]{2}{*}{ IL-6 } & LABF & 14 & 235.9 & 273.8 & 50.8 & 14.2 & 21.0 & 3.300 & 0.0026 \\
\hline & OABF & 16 & 965.4 & 875.9 & 71.8 & 19.8 & & & \\
\hline \multirow[t]{2}{*}{ IL-8 } & LABF & 14 & 374.2 & 463.6 & 65.7 & 12.6 & 10.6 & 1.960 & 0.0600 \\
\hline & OABF & 16 & 565.5 & 790.1 & 76.3 & 16.4 & & & \\
\hline \multirow[t]{2}{*}{ CRP } & LABF & 14 & 362.5 & 464.9 & 55.8 & 18.5 & 2.4 & 0.390 & 0.6993 \\
\hline & OABF & 16 & 554.4 & 594.3 & 58.1 & 14.8 & & & \\
\hline
\end{tabular}

Abbreviation: SD, standard deviation. 
Table 3 The effect of laparoscopic aortobifemoral bypass (LABF) versus open aortobifemoral bypass (OABF) on serum levels of interleukin-6 (IL-6), IL-8, and C-reactive protein (CRP), controlling for the confounding effect of coronary heart disease, using the general estimated equations (GEE) model

\begin{tabular}{|c|c|c|c|c|c|}
\hline Inflammation marker & Coefficient & SE & $\mathbf{Z}$ & $P$-value & Confounding effect \\
\hline \multicolumn{6}{|l|}{ IL-6 } \\
\hline Crude effect & -0.7024 & 0.2484 & -2.83 & 0.005 & \\
\hline Adjusted for CHD & -0.6407 & 0.2488 & -2.58 & 0.010 & $8.8 \%$ \\
\hline \multicolumn{6}{|l|}{ IL-8 } \\
\hline Crude effect & -0.2695 & 0.1973 & -1.37 & 0.172 & \\
\hline Adjusted for CHD & -0.2360 & 0.2005 & -1.18 & 0.237 & $5.3 \%$ \\
\hline \multicolumn{6}{|l|}{ CRP } \\
\hline Crude effect & -0.0963 & 0.3739 & -0.26 & 0.797 & \\
\hline Adjusted for $\mathrm{CHD}$ & -0.0562 & 0.3808 & -0.15 & 0.883 & $41.6 \%$ \\
\hline
\end{tabular}

Note: The confounding effect is quantified using the formula: (Coefficient adjusted $_{\text {- Coefficient }}$ crude )/Coefficient crude $\times 100$.

Abbreviations: SE, standard error; CHD, coronary heart disease.

Table 4 Operation-related parameters for patients treated with either totally laparoscopic or open aortobifemoral bypass for severe aortoiliac occlusive disease

\begin{tabular}{|c|c|c|c|}
\hline Parameters & $\begin{array}{l}\text { Laparoscopy } \\
(N=14)\end{array}$ & $\begin{array}{l}\text { Open surgery } \\
(N=16)\end{array}$ & P-value \\
\hline Operation time (minutes), median (IQR) & $216(195-235)$ & $202(169-230)$ & $0.2600^{\mathrm{a}}$ \\
\hline Blood loss during surgery (mL), median (IQR) & $275(150-600)$ & $\mathrm{I}, 000(575-\mathrm{I}, \mathrm{I} 50)$ & $0.0300^{\mathrm{a}}$ \\
\hline Suprarenal clamping, N (\%) & I (7.I) & I (6.3) & $0.9200^{\mathrm{b}}$ \\
\hline Aortic clamping time (minutes), ${ }^{\mathrm{c}}$ median (IQR) & $43(4 I-52)$ & $30(20-38)$ & $0.0002^{\mathrm{a}}$ \\
\hline
\end{tabular}

Notes: Statistics: aMann-Whitney $U$-test; ' ${ }^{2}$ isher's exact $t$-test; ' caortic clamping time defined as: time from cross-clamping of the aorta above the proximal anastomosis until the clamp is moved to the proximal end of the graft.

Abbreviation: IQR, interquartile range.

Table 5 Clinical outcome after laparoscopic aortobifemoral bypass (LABF) versus open aortobifemoral bypass (OABF)

\begin{tabular}{llll}
\hline Clinical outcome & Laparoscopy & Open surgery & P-value \\
\hline Length of stay in hospital (days), median (IQR) & $5.0(4.0-6.0)$ & $9.0(6.5-11.0)$ & $0.00 I^{\mathrm{a}}$ \\
Thirty-day mortality, N & 0 & 0 & $4(25)$ \\
Thirty-day systemic morbidity, ${ }^{\mathrm{c}} \mathrm{N}(\%)$ & $\mathrm{I}(7)$ & $0.210^{\mathrm{b}}$ \\
\hline
\end{tabular}

Notes: Statistics: aMann-Whitney U-test; 'Fisher's exact test; and 'systemic morbidity is defined as systemic complications including systemic infection, ileus, sepsis, acute respiratory distress syndrome, multiple organ failure, renal failure, myocardial infarction, and/or cerebral infarction/hemorrhage. Not including local morbidity defined as local wound infection, lymphatic discharge from wound, simple urinary tract infections, pneumonia, or graft occlusion.

Abbreviation: IQR, interquartile range.

and phagocytosis. ${ }^{35}$ These reactions to surgical trauma are reflected in our patients, who showed an increase in the serum levels of all three inflammatory markers in both groups after surgery (Figures 2-4).

Timing of blood samples is essential for the detection of serial changes in the serum levels of inflammatory markers. In our study population, we did not take any blood samples between 24 hours postoperatively and the discharge of the patient. Watt et al found in their new systematic review from 2015 that serum levels of CRP peak after 24 hours postoperatively. Additional blood samples for CRP in the postoperative period could have been helpful in detecting the serum changes more efficiently. ${ }^{3}$

Proinflammatory markers were analyzed at the time of discharge for all the patients. However, the patients were discharged much earlier in the LABF group when compared with the OABF group (Table 5), and the variation in sampling time point did not allow a comparison.

The serum concentrations of different cytokines may vary according to location of the sampling site. Concentrations in the portal vein are higher after abdominal surgery. ${ }^{36,37} \mathrm{In}$ this study, the samples were taken primarily from arterial catheter, but in a few cases, they had to be taken from a central venous catheter or peripheral vein. This difference in sampling site could have influenced the serum concentrations of the inflammatory cytokines.

This is a substudy of a randomized trial, which could affect the distribution of known and unknown confounding factors between the two groups, resulting in confounding bias and random effects. There were minor differences in the baseline characteristics, and these factors were deemed as potential confounders. CHD was the most significant 
confounder, and we investigated the confounding effect of CHD in our final multivariate model. The confounding effect on IL-6 was minor (Table 3). We know that the GEE model works best if the number of clusters (patients) is large ( $\mathrm{n}>50$ ), the number of observations in a cluster is small, and the measurements are taken at the same time for all the subjects. ${ }^{28}$ Hence, time points four and six had to be removed from the GEE model.

All the inflammatory markers point in the same direction, indicating less inflammatory response after laparoscopic surgery. However, the population of patients in each group was small, and our participants were included from three different hospitals, which may also have influenced the results. The generalizability and external validity of such a small study are questionable, but we have no indication that there was any population bias. The multiplicity of analyses compared to the number of participants could be problematic, and larger trials with patient inclusion based on power analysis may be an aim for further research.

However, randomization and lack of missing values add to the strength of this study. The repeated measurements are significant to capture the serum peak levels, and the statistical analysis comparing AUC is superior to comparing the difference in repeated correlated measurements. ${ }^{27}$ Also, to the authors' knowledge, this is the first randomized trial on this subject.

An understanding of the inflammatory response to surgery is important to clinicians in the treatment and prevention of complications. ${ }^{38}$ Different therapeutic regimes have been suggested to balance the reaction between proinflammatory response and immunosuppression and restore immune homeostasis. Nevertheless, reducing the initial trauma has proven to be the most logical strategy. ${ }^{39,40}$ Our results indicate that $\mathrm{LABF}$ is a less invasive technique than OABF.

\section{Conclusion}

In this substudy of a randomized controlled trial comparing $\mathrm{LABF}$ and $\mathrm{OABF}$ surgeries, we found a decreased perioperative inflammatory response, measured by comparing AUC for serum IL-6. An adequately powered randomized trial could be an aim for further research.

\section{Acknowledgments}

We thank all the participating hospitals and staff for all their help, especially the biochemical laboratories of the local hospitals in Kristiansand, Fredrikstad, and Oslo, who provided help in collecting and storing the blood samples, and the Hormone Laboratory, Oslo University Hospital, who analyzed all the samples.

\section{Disclosure}

The authors report no conflicts of interest in this work.

\section{References}

1. Lennard TWJ, Shenton BK, Borzotta A, et al. The influence of surgical operations on components of the human immune system. Br J Surg. 1985;72(10):771-776.

2. Jawa RS, Anillo S, Huntoon K, Baumann H, Kulaylat M. Interleukin-6 in surgery, trauma, and critical care Part II: clinical implications. $J$ Intensive Care Med. 2011;26(2):73-87.

3. Watt DG, Horgan PG, McMillan DC. Routine clinical markers of the magnitude of the systemic inflammatory response after elective operation: a systematic review. Surgery. 2015;157(2):362-380.

4. Baigrie RJ, Lamont PM, Kwiatkowski D, Dallman MJ, Morris PJ. Systemic cytokine response after major surgery. Br J Surg. 1992;79(8): 757-760.

5. Roumen RM, Hendriks T, van der Ven-Jongekrijg J, et al. Cytokine patterns in patients after major vascular surgery, hemorrhagic shock, and severe blunt trauma. Relation with subsequent adult respiratory distress syndrome and multiple organ failure. Ann Surg. 1993;218(6):769-776.

6. Sun T, Wang X, Liu Z, Chen X, Zhang J. Plasma concentrations of proand anti-inflammatory cytokines and outcome prediction in elderly hip fracture patients. Injury. 2011;42(7):707-713.

7. Cuschieri J, Bulger E, Schaeffer V, et al. Early elevation in random plasma IL-6 after severe injury is associated with development of organ failure. Shock. 2010;34(4):346-351.

8. Novitsky YW, Litwin DE, Callery MP. The net immunologic advantage of laparoscopic surgery. Surg Endosc. 2004;18(10):1411-1419.

9. Vittimberga FJJ, Foley DP, Meyers WC, Callery MP. Laparoscopic surgery and the systemic immune response. Ann Surg. 1998;227(3):326-334.

10. Swartbol P, Truedsson L, Norgren L. The inflammatory response and its consequence for the clinical outcome following aortic aneurysm repair. Eur J Vasc Endovasc Surg. 2001;21(5):393-400.

11. Galle C, De Maertelaer V, Motte S, et al. Early inflammatory response after elective abdominal aortic aneurysm repair: a comparison between endovascular procedure and conventional surgery. J Vasc Surg. 2000;32(2):234-246.

12. Gupta A, Watson DI. Effect of laparoscopy on immune function. $\mathrm{Br} J$ Surg. 2001;88(10):1296-1306.

13. Sietses C, Beelen RH, Meijer S, Cuesta MA. Immunological consequences of laparoscopic surgery, speculations on the cause and clinical implications. Langenbecks Arch Surg. 1999;384(3):250-258.

14. Sammour T, Kahokehr A, Chan S, Booth RJ, Hill AG. The humoral response after laparoscopic versus open colorectal surgery: a metaanalysis. J Surg Res. 2010;164(1):28-37.

15. Sido B, Teklote J-R, Hartel M, Friess H, Büchler MW. Inflammatory response after abdominal surgery. Best Pract Res Clin Anaesthesiol. 2004;18(3):439-454.

16. Bruls S, Quaniers J, Tromme P, Lavigne JP, Van Damme H, Defraigne JO. Comparison of laparoscopic and open aortobifemoral bypass in the treatment of aortoiliac disease. Results of a contemporary series (2003-2009). Acta Chir Belg. 2012;112(1):51-58.

17. Tiek J, Remy P, Sabbe T, et al. Laparoscopic versus open approach for aortobifemoral bypass for severe aortoiliac occlusive disease - a multicentre randomised controlled trial. Eur J Vasc Endovasc Surg. 2012;43(6):711-715.

18. Cau J, Ricco JB, Corpataux JM. Laparoscopic aortic surgery: techniques and results. JVasc Surg. 2008;48(6 Suppl):37S-44S; discussion $45 \mathrm{~S}$.

19. Kazmi SSH, Jørgensen JJ, Sundhagen JO, et al. A comparative cohort study of totally laparoscopic and open aortobifemoral bypass for the treatment of advanced atherosclerosis. Vasc Health Risk Manag. 2015;11:541-547.

20. Kolvenbach R, Deling O, Schwierz E, Landers B. Reducing the operative trauma in aortoiliac reconstructions - a prospective study to evaluate the role of video-assisted vascular surgery. Eur J Vasc Endovasc Surg. 1998;15(6):483-488. 
21. Norgren L, Hiatt WR, Dormandy JA, Nehler MR, Harris KA, Fowkes FG. Inter-society consensus for the management of peripheral arterial disease (TASC II). J Vascu Surg. 2007;45(Suppl S):S5-S67.

22. Gomez. Global initiative for chronic obstructive lung disease (GOLD) guidelines for chronic obstructive pulmonary disease. Curr Opin Pulm Med. 2002;8(2):81-86.

23. Fourneau I, Lerut P, Sabbe T, Houthoofd S, Daenens K, Nevelsteen A. The learning curve of totally laparoscopic aortobifemoral bypass for occlusive disease. How many cases and how safe? Eur JVasc Endovasc Surg. 2008;35(6):723-729.

24. Coggia M, Bourriez A, Javerliat I, Goeau-Brissonniere O. Totally laparoscopic aortobifemoral bypass: a new and simplified approach. Eur J Vasc Endovasc Surg. 2002;24(3):274-275.

25. Swartbol P, Pärsson H, Truedsson L, Sjöholm A, Norgren L. Aortobifemoral surgery induces complement activation and release of interleukin-6 but not tumour necrosis factor-alpha. Cardiovasc Surg. 1996; 4(4):483-491.

26. Crockson RA, Payne CJ, Ratcliff AP, Soothtll JF. Time sequence of acute phase reactive proteins following surgical trauma. Clin Chim Acta. 1966;14(4):435-441.

27. Matthews JN, Altman DG, Campbell MJ, Royston P. Analysis of serial measurements in medical research. BMJ. 1990;300(6719):230-235.

28. Zeger SL, Liang K-Y, Albert PS. Models for longitudinal data: a generalized estimating equation approach. Biometrics. 1988;44(4):1049-1060.

29. Lin E, Calvano SE, Lowry SF. Inflammatory cytokines and cell response in surgery. Surgery. 2000;127(2):117-126.

30. Jawa RS, Anillo S, Huntoon K, Baumann H, Kulaylat M. Analytic review: interleukin-6 in surgery, trauma, and critical care: part I: basic science. J Intensive Care Med. 2011;26(1):3-12.
31. Yahara N, Abe T, Morita K, Tangoku A, Oka M. Comparison of interleukin-6, interleukin-8, and granulocyte colony-stimulating factor production by the peritoneum in laparoscopic and open surgery. Surg Endosc. 2002;16(11):1615-1619.

32. Van Zee KJ, Fischer E, Hawes AS, et al. Effects of intravenous IL-8 administration in nonhuman primates. $J$ Immunol. 1992;148(6): 1746-1752.

33. Sakamoto K, Arakawa H, Mita S, et al. Elevation of circulating interleukin 6 after surgery: factors influencing the serum level. Cytokine. 1994;6(2):181-186

34. Moshage HJ, Roelofs HMJ, van Pelt JF, et al. The effect of interleukin-1, interleukin- 6 and its interrelationship on the synthesis of serum amyloid A and C-reactive protein in primary cultures of adult human hepatocytes. Biochem Biophys Res Commun. 1988;155(1):112-117.

35. Black S, Kushner I, Samols D. C-reactive protein. J Biol Chem. 2004; 279(47):48487-48490.

36. Mainous MR, Ertel W, Chaudry IH, Deitch EA. The gut: a cytokinegenerating organ in systemic inflammation? Shock. 1995;4(3): 193-199.

37. Baigrie RJ, Lamont PM, Whiting S, Morris PJ. Portal endotoxin and cytokine responses during abdominal aortic surgery. Am J Surg. 1993; 166(3):248-251.

38. Kohl BA, Deutschman CS. The inflammatory response to surgery and trauma. Curr Opin Crit Care. 2006;12(4):325-332.

39. Menger MD, Vollmar B. Surgical trauma: hyperinflammation versus immunosuppression? Langenbecks Arch Surg. 2004;389(6): 475-484.

40. Ni Choileain N, Redmond HP. Cell response to surgery. Arch Surg. 2006; 141(11):1132-1140.
Vascular Health and Risk Management

\section{Publish your work in this journal}

Vascular Health and Risk Management is an international, peerreviewed journal of therapeutics and risk management, focusing on concise rapid reporting of clinical studies on the processes involved in the maintenance of vascular health; the monitoring, prevention and treatment of vascular disease and its sequelae; and the involvement of

\section{Dovepress}

metabolic disorders, particularly diabetes. This journal is indexed on PubMed Central and MedLine. The manuscript management system is completely online and includes a very quick and fair peer-review system, which is all easy to use. Visit http://www.dovepress.com/ testimonials.php to read real quotes from published authors. 